\title{
EFFECT OF ZEOLUX USE ON SAGE (SALVIA OFFICINALIS) PLANT IRRIGATED BY FRESH AND RO REJECT WATERS
}

\author{
AL-TABBAL J. ${ }^{1}$ \\ AL-ZBOON K. ${ }^{2}$ \\ AL-ZOUBY J. ${ }^{2}$ \\ AL-SMADI B. ${ }^{3}$ \\ AMMARY B.Y. ${ }^{2, *}$
}

\author{
${ }^{1}$ Nutrition and Food processing Department \\ Balqa Applied University \\ Huson College, Huson 21510 Jordan \\ ${ }^{2}$ Water and Environmental Engineering Department \\ Balqa Applied University \\ Huson College, Huson 21510 Jordan \\ ${ }^{3}$ Civil Engineering Department \\ The University of Jordan, Amman 11942, Jordan
}

Received: 05/12/2014

Accepted: $21 / 05 / 2016$

Available online: 01/06/2016 *to whom all correspondence should be addressed: e-mail: bammary@yahoo.com

\section{ABSTRACT}

The effect of Zeolux use as soil amendment on the yield and some of the agronomic traits of a home garden plant, Sage (Salvia officinalis), irrigated by either fresh or RO reject waters was studied. Clay and different combinations of clay-Jordanian zeolux were compared for that purpose. Each combination was divided into two subgroups at randomized experiment and irrigated with either fresh or RO reject waters. The combination of $75 \%$ clay and $25 \%$ zeolux irrigated with fresh water produced the best results in terms of plant height, number of branches, fresh weight, dry weight and root dry weight of sage plant. The results indicate that the use of RO reject water causes significant reduction in all the studied parameters above. The use of zeolux did not reduce the harmful effects of the saline water used for irrigation on the yield of sage.

Keywords: Saline water, RO, Tuff, Reuse, Irrigation, Salvia officinalis, Sage

\section{Introduction}

Natural zeolites (zeolux) are among the minerals often used as substrates for plant growth such as seedling production, rooting of cuttings, potting of ornamental plants, etc. Natural zeolites' strong sorption properties, high cation exchange capacity (CEC) and rich macro and micro nutrients content make them an attractive alternative to peat moss and other natural products used in the industrial production of substrates. Natural zeolites have also been used for a long time to improve soil quality. Farmers add zeolites to the soil to control soil pH and to improve ammonium retention (Dwyer and Dyer, 1984). Other finding revealed that zeolite could be useful in decreasing the negative effects of high salinity (Noori et al., 2006). Soil salinity is a major abiotic factor limiting crop production. The use of zeolites as a soil amendment may mitigate the effects of salinity stress on plants. The objectives of this study are to determine the effects that Jordanian tuff (zeolux) use as a soil amendment has on the yield and some of the agronomic traits of Sage (Salvia officinalisvar). The effects were studied under two types of irrigation waters, namely fresh and reverse osmosis (RO) reject waters. The capability of zeolux to reduce the detrimental effects of such saline water on the growth of sage was also an objective of this study. 
Sage plant (Salvia officinalis var. purpurascens) is an evergreen sub shrub that belongs to the Mediterranean region. Sage has been used for medicinal purposes, including as an antihydrotic, spasmolytic, antiseptic and as an anti-inflammatory, and in the treatment of mental and nervous conditions (Baricevic and Bartol, 2000). Sage has also been used traditionally in food preparation. The production of plants using saline water such as RO reject water could have numerous adverse effects on growth, morphology, and survival of the plants (Hasegawa et al., 2000). Salinity in soil becomes a problem when the total amount of salts which accumulate in the root zone is high enough to negatively affect plant growth. Accumulation of salts in the root zone affects plant performance through creation of water deficit and disruption of ion homeostasis (Bauder and Brock, 2001; Munns, 2002) which in turn cause metabolic dysfunctions. These stresses change hormonal status and impair basic metabolic processes (Munns, 2002; Loreto et al., 2003) resulting in growth inhibition and reduction in yield (Maas, 1993).

Irrigation management practices aim at using poor quality waters in agriculture by maintaining salt accumulation in the root zone at lower levels. Therefore, appropriate cultural practices may dramatically improve the performance of crops in saline environments. Soil permeability problems may be prevented or corrected by using soil or water amendments. Zeolux was used in this study as a soil amendment in an attempt to reduce the detrimental effect of saline water on the growth of sage. In the present study RO reject water from an inland desalination plant was used and compared with fresh water for sage irrigation in the presence and absence of zeolux. Reject brine has been used for fish farming and irrigation of forage shrub and crops in South America (Sánchez et al., 2015).

A number of parameters have been used to evaluate the success of plantations. These include, shoot or root height (Kaya et al., 2006), shoot length to root length ratio (Tadros et al., 2012), diameter, dry mass, or the ratio of shoot dry mass to root dry mass (Bernier et al., 1995; Tadros et al., 2012). An imbalance in shoot to root ratio can cause transplanting shock (Bernier et al., 1995). The root mass is correlated with the ability of a plant to absorb water, while the shoot mass is correlated with the amount of water a plant losses through transpiration (Wilson, 1988). Therefore, the shoot to root ratio has been used as a measure to evaluate the drought avoidance potential, with those having a low shoot to root ratio values, have a higher drought avoidance potential (Bernier et al., 1995). For the same plant, however, an equilibrium between the amount of shoot to the amount of root (shoot: root ratio) must be present (Wilson, 1988).

\section{Methodology}

\subsection{RO brine water}

The brine water was taken from the reject stream of a water desalination plant located in the city of Zarqa, Jordan.

Table 1. Characteristics of the RO brine water.

\begin{tabular}{|c|c|}
\hline Parameter & Average \\
\hline $\mathrm{pH}$ & 8.0 \\
\hline $\mathrm{EC}\left(\mathrm{ds} \mathrm{\textrm {cm } ^ { - 1 } )}\right.$ & 7 \\
\hline TDS (mg l-1) & 4460 \\
\hline $\mathrm{TH}\left(\mathrm{mgCaCO}_{3} \mathrm{I}^{-1}\right)$ & 2850 \\
\hline $\mathrm{Ca}\left(\mathrm{mg} \mathrm{l}^{-1}\right)$ & 429 \\
\hline $\mathrm{Mg}\left(\mathrm{mg} \mathrm{l}^{-1}\right)$ & 427 \\
\hline $\mathrm{Cl}\left(\mathrm{mg} \mathrm{l}^{-1}\right)$ & 1869 \\
\hline $\mathrm{Na}\left(\mathrm{mg} \mathrm{l}^{-1}\right)$ & 1300 \\
\hline $\mathrm{K}\left(\mathrm{mg} \mathrm{l}^{-1}\right)$ & 26 \\
\hline $\mathrm{NO}_{3}\left(\mathrm{mg} \mathrm{l}^{-1}\right)$ & 161 \\
\hline $\mathrm{PO}_{4}\left(\mathrm{mg} \mathrm{l}^{-1}\right)$ & 0.0 \\
\hline $\mathrm{SO}_{4}\left(\mathrm{mg} \mathrm{l}^{-1}\right)$ & 572 \\
\hline $\mathrm{HCO}_{3}\left(\mathrm{mg} \mathrm{CaCO} \mathrm{I}^{-1}\right)$ & 270 \\
\hline
\end{tabular}


The plant consists of two stages of RO membranes with a capacity of $600 \mathrm{~m}^{3} \mathrm{~h}^{-1}$. The treatment process includes: chlorination to remove ammonia, coagulation, equalization, sand filtration, dechlorination, $\mathrm{pH}$ adjustment, anti-scaling unit, 5 micron filtration, and RO units.

The source of water is brackish groundwater (TDS= $2001 \mathrm{mg} \mathrm{l}^{-1}$ ) obtained from three wells located in the vicinity of the plant. The depth of these wells is $300 \mathrm{~m}$. The raw water has high concentrations of salinity (TDS), hardness (TH), and $\mathrm{NH}_{4}{ }^{+}$and it must be treated before it can be used for potable purposes. $\mathrm{RO}$ reject water samples were analyzed in triplicate and the results are reported in Table 1. All of the analyses were carried out following the standard methods for the examination of water and wastewater (APHA, 1995).

\subsection{Preparation of pots}

Pots with a diameter of $30 \mathrm{~cm}$ and a depth of $45 \mathrm{~cm}$ were prepared to prevent water loss. They were divided into five groups with the first group containing clay soil, as control. The second group contains a mixture of $75 \%$ clay soil and $25 \%$ zeolux, while the third group contains a mixture of $50 \%$ to $50 \%$. The fourth group contains a mixture of $25 \%$ clay soil and $75 \%$ zeolux, while the final group consists of $100 \%$ zeolux. Each group was divided into two subgroups at randomized experiment and irrigated with two types of waters (fresh water and brine water). Each experiment was conducted in triplicate and the averages of these experiments are reported. Two seedling of Salvia officinalis were planted in each pot. Soil water potential was maintained by frequently weighing the pots. An amount of water equal to the weight loss was added from each type of water. Plants were irrigated to the pot capacity for one week before starting the experiment in order to improve root development.

\subsection{Yield and yield components measurement}

Plants were harvested after 150 days from transplanting. Shoots were removed from roots at the soil surface. Yield and yield components were measured for the two plants in each pot. The plants were harvested during the growing season by cutting the plants and the different vegetative growth parameters were recorded as follows: plant height (PH), number of branches/plant, (NB), shoot fresh weight (SFW), shoot dry weight (SDW), root dry weight (RDW) and shoot dry weight to root dry weight ratio (SDR/RDW).

\subsection{Statistical analysis}

Statistical analyses were performed using ANOVA and the least significant deference test (LSD) using SAS statistical software (SAS, 2002).

\section{Results and discussion}

\subsection{Effect of Soil Type:}

\subsubsection{Fresh Water as Irrigation Water}

Table 2 shows the effects that the addition of zeolux on clay has on a number of parameters related to the growth of sage plant. Table 2 shows that the addition of zeolux has a significant effect on most of the parameters studied when fresh water was used as irrigation water.

Figure 1 , shows that the soil that has $25 \%$ zeolux and $75 \%$ clay produced the largest plant height (PH) compared to other clay-zeolux combinations. In Figure 1, and all subsequent figures, the zeolux-clay combination that produced the largest plant height was assigned the letter $A$ to indicate that this combination has scored the largest PH. In Figure 1, the other zeolux-clay combinations were assigned the letter B. The meaning of these letters is as follows. To evaluate the differences between PH that occurred as a result of using different percentages of zeolux in soil, the value of Fisher's Least Square Difference (LSD) at 0.05 probability level was computed and found to be equal to $(3.29 \mathrm{~cm})$, as shown in Table 2 for the plant height. As the letter A was assigned to a PH of $52.25 \mathrm{~cm}$ as shown above to $(25 \%$ zeolux and $75 \%$ clay), a zeolux-clay combination that produced a PH that is lower than $52.25 \mathrm{~cm}$ by LSD $(3.29 \mathrm{~cm}$ in Table 2) would be assigned the letter B. In other words, a PH of less than $48.96 \mathrm{~cm}(52.25 \mathrm{~cm}$ minus $3.29 \mathrm{~cm})$ would be assigned the letter $B$. As the combination that produced the second score of $(41.75 \mathrm{~cm})$ was 
( $50 \%$ zeolux: $50 \%$ clay), as shown in Table 2 , this combination was assigned the letter B. The letter B as compared to the letter A means that there is a significant difference between these two zeolux-clay combinations according to Fisher's LSD at 0.05 probability. A combination that produces a PH that is lower than $(41.75 \mathrm{~cm})$ by the value of LSD would be assigned the letter $\mathrm{C}$. In this case, as Table 2 shows for the $\mathrm{PH}$, all the other combinations scored a PH that is closer to the $(41.75 \mathrm{~cm})$ than the LSD, and therefore all the other zeolux-clay combinations were assigned the letter $\mathrm{B}$. The four combinations that were assigned the letter B in Figure 1 are therefore not significantly different according to LSD at 0.05 probability level.

Table 2: Mean plant height (PH), number of branches per plant (NB), shoot fresh weight (SFW), shoot dry weight (SDW), root dry weight (RDW) and the ratio between shoot dry weight and root dry weight (SDW/RDW) of Sage Plant (Salvia officinalis) irrigated with two types of water and planted in different soil mixtures.

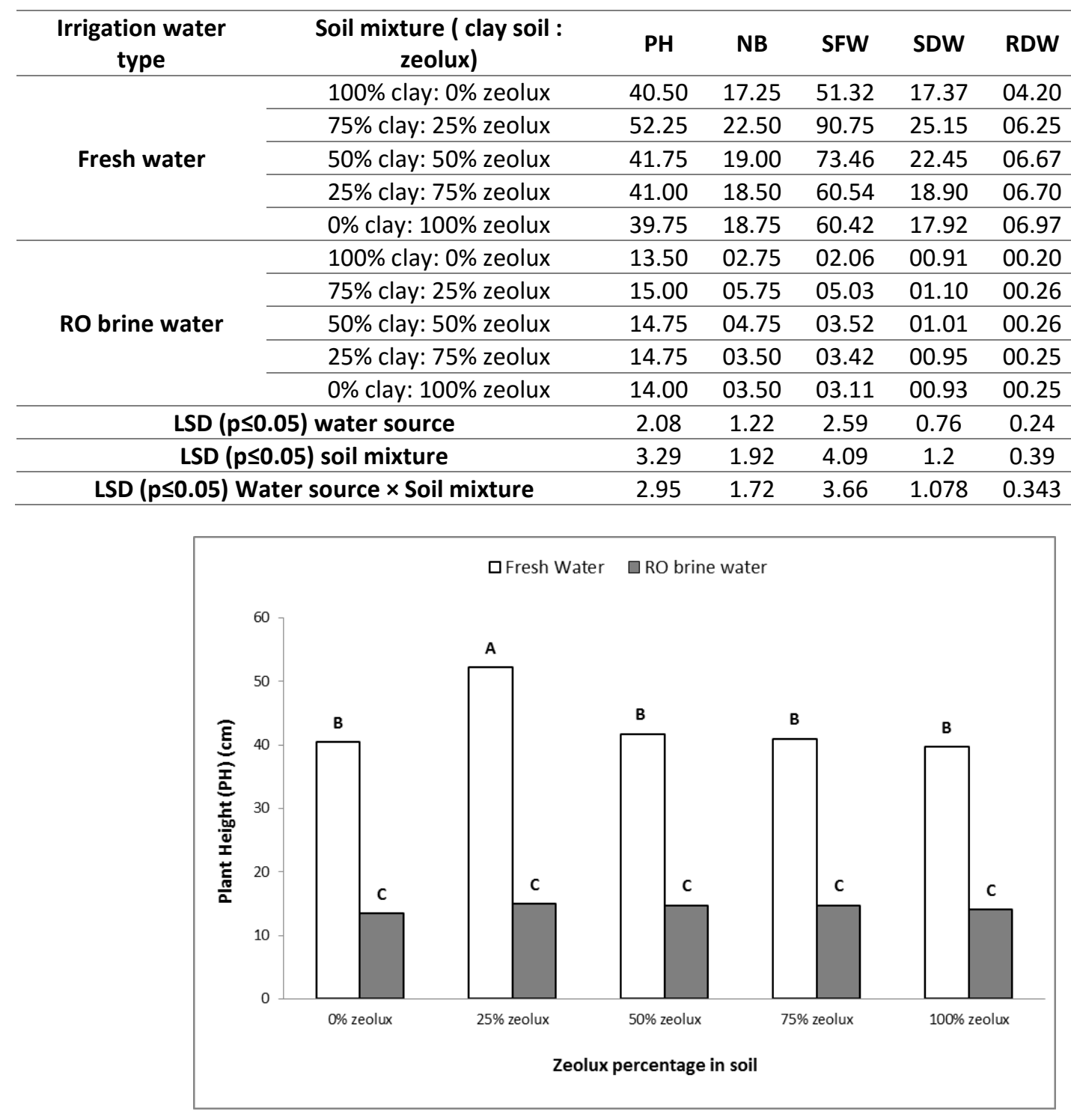

Figure 1. Effect of zeolux mixing with clay on sage plant height

Figure 2 shows that, again, the ( $25 \%$ zeolux: $75 \%$ clay) soil resulted in the highest number of branches (assigned the letter A). The zeolux-clay combination that produced the second highest number of branches was ( $50 \%$ zeolux: $50 \%$ clay). This combination was assigned the letter B to indicate that the difference was significant according to LSD at 0.05 probability level. The combination that produced the lowest number of branches was when no zeolux was used (0\% zeolux: $100 \%$ clay). As the difference was significant from the (50\% zeolux: $50 \%$ clay) combination, this combination was assigned the letter $\mathrm{C}$. The 
other two combinations in Figure 2 were assigned the letters BC. A letter BC indicates that the combination is not significantly lower than $B$ and not significantly higher than $C$ according to LSD at 0.05 probability level.

Figures 3 and 4 show that the (25\% zeolux: $75 \%$ clay) soil produced the highest shoot fresh weight and the highest shoot dry weight (assigned the letter A), respectively. On the other hand, (0\% zeolux: $100 \%$ clay) soil produced the lowest values in both parameters (assigned the letter D). The difference was significant according to LSD at 0.05 probability level. Figures 3 and 4 also show that all soil mixtures that have zeolux ( $25 \%, 50 \%, 75 \%$, and $100 \%$ zeolux) produced higher shoot fresh weight and higher shoot dry weight that when clay was used alone ( $0 \%$ zeolux: $100 \%$ clay). The difference was significant according to LSD (assigned the letters B and C in Figures 3 and 4 ) except when $100 \%$ zeolux was used for the shoot dry weight (assigned the letter CD in Figure 4).

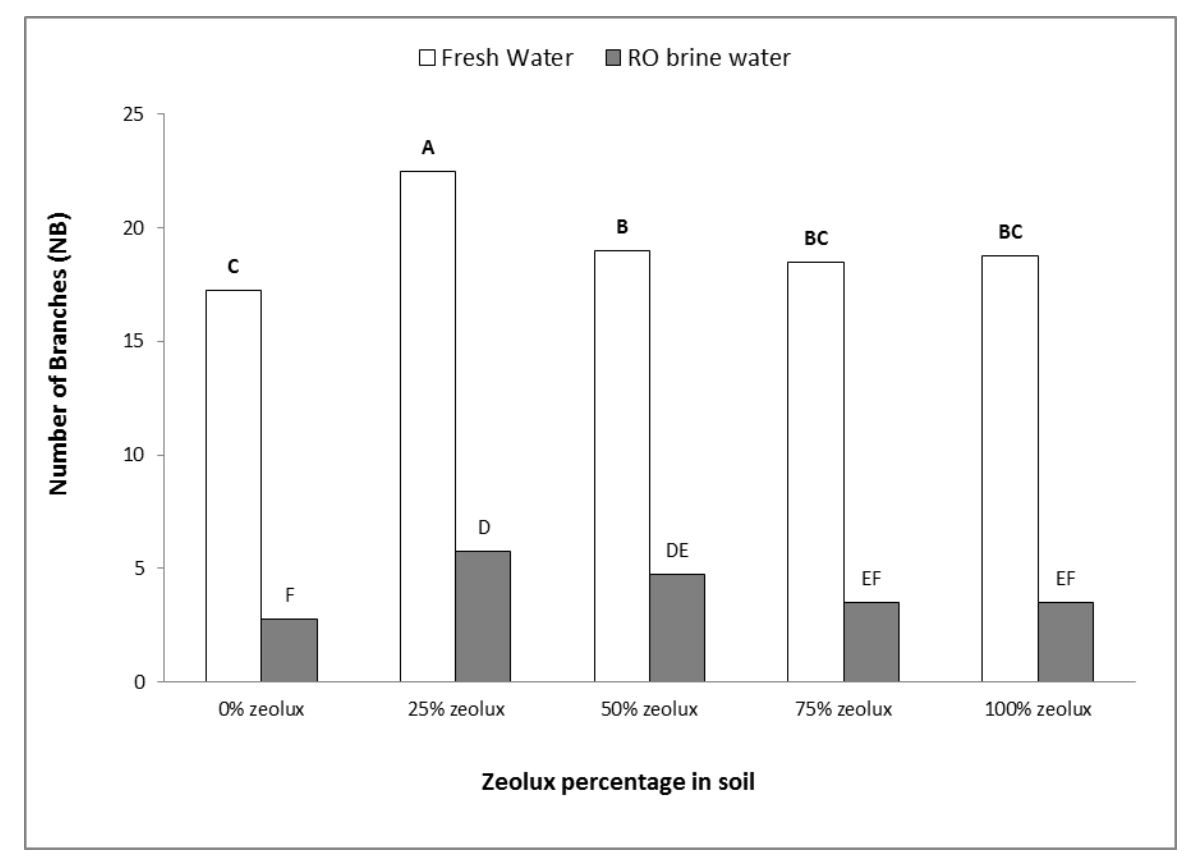

Figure 2. Effect of zeolux mixing with clay on number of branches of sage

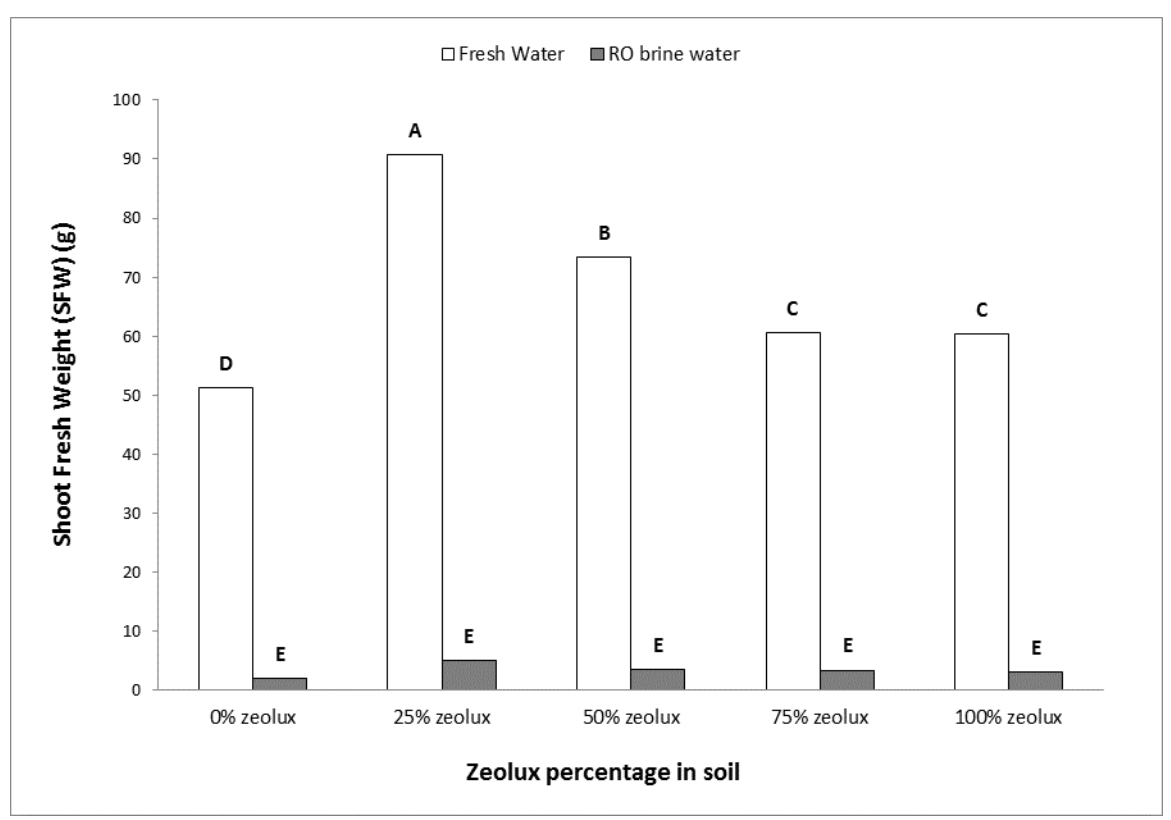

Figure 3. Effect of zeolux mixing with clay on sage shoot fresh weight 


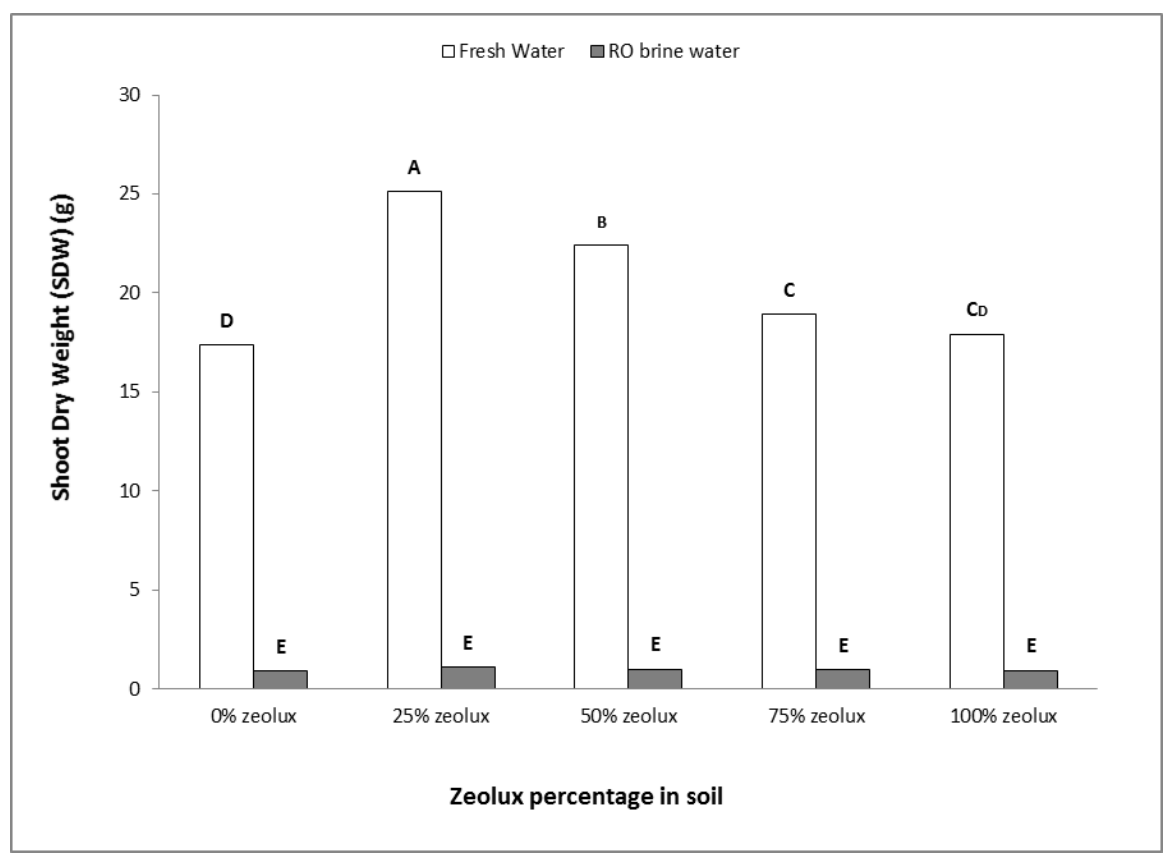

Figure 4. Effect of zeolux mixing with clay on sage shoot dry weight

Zeolux use (at $25 \%, 50 \%, 75 \%$, and $100 \%$ ) has increased significantly the root dry weight of sage (assigned $A$ and $B$ ) as compared to clay soil alone (assigned C) as shown in Figure 5 . The (50\% zeolux: $50 \%$ clay) soil produced significantly higher value of root dry weight than the (25\% zeolux: $75 \%$ clay) soil. Higher zeolux percentages ( $75 \%$ and $100 \%$ ), however, have not improved the root dry weight significantly according to LSD than the $50 \%$ zeolux percentage. Zeolux addition at $25 \%, 50 \%, 75 \%$, and $100 \%$ percentages of clay soil resulted, respectively, in $48.8 \%, 58.8 \%, 59.5 \%$ and $66 \%$ increase in root dry weight compared to clay soil alone.

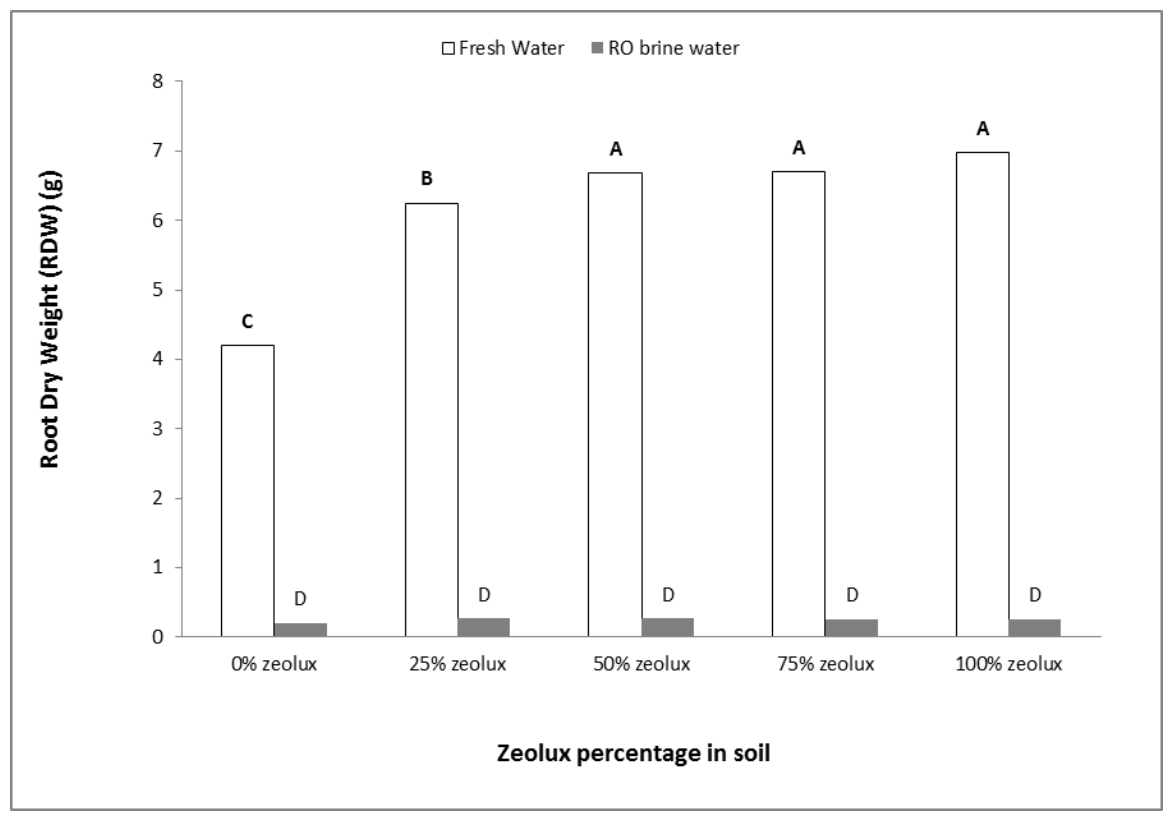

Figure 5. Effect of zeolux mixing with clay on sage root dry weight

In summary, when fresh water is used for irrigation, and as Figures 1-5 show, the addition of zeolux to clay improved (or at least gave the same effects) the agronomic traits of plants grown in the soil. Sage plants irrigated with fresh water responded positively to zeolux addition to soil especially at a mixture of 
( $25 \%$ zeolux: $75 \%$ clay). Zeolux addition to clay at $25 \%$ resulted in $29 \%$ increase in plant height, $76 \%$ in shoot fresh weight, $44.9 \%$ in shoot dry weight, and $49 \%$ in root dry weight of the plant.

The shoot dry weight to root dry weight (SDW/RDW) for different zeolux percentages in soil are shown in Figure 6. Clay soil with no zeolux added produced the highest SDW/RDW while soil with $100 \%$ zeolux produced the lowest value. As zeolux percentage in soil increases, the SDW/RDW decreases. As has been mentioned earlier, low shoot to root ratio is indicative of a higher drought avoidance potential (Bernier et al., 1995). In other words, the presence of zeolux has improved the drought resistance of sage plant.

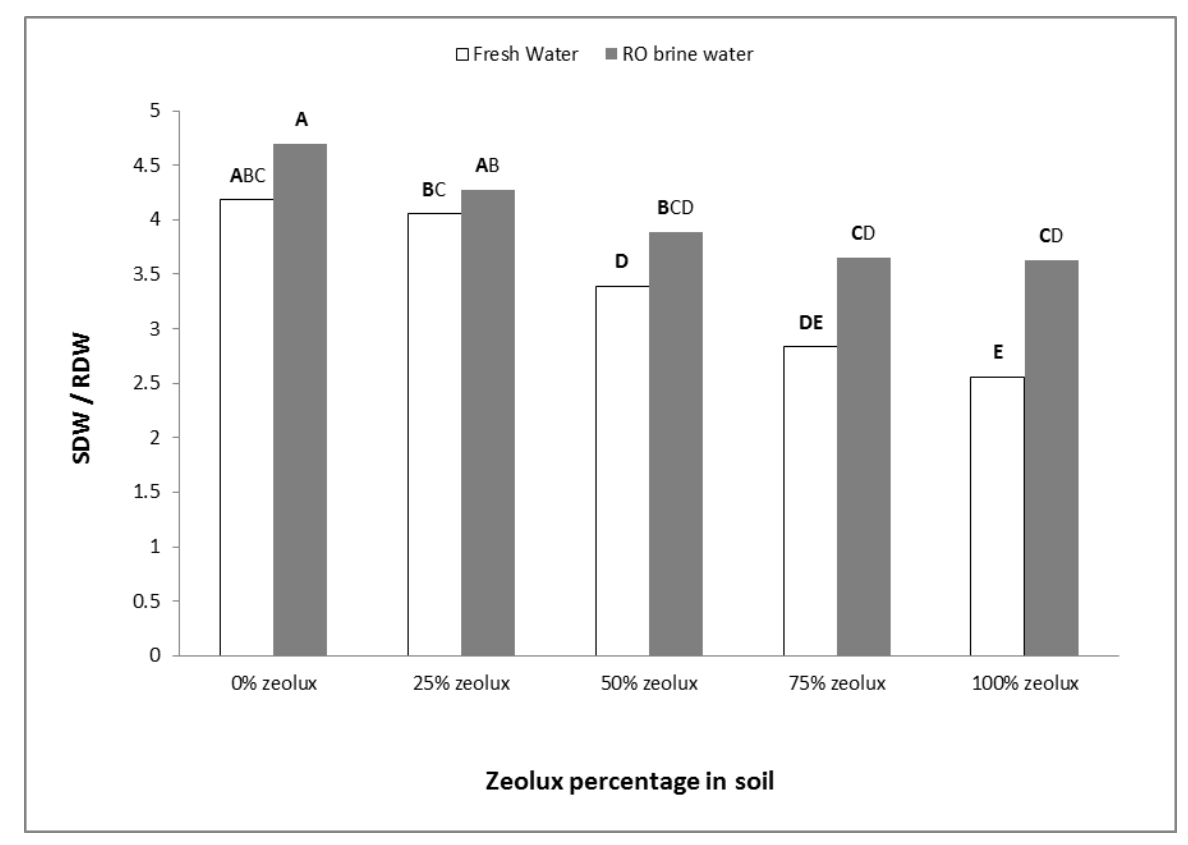

Figure 6. Effect of zeolux mixing with clay on sage shoot dry weight to root dry weight (SDW/RDW)

The effect of zeolux use may be associated with water and nutrient dynamics in zeolux mixed soils. These results are in agreement with that obtained for Brassica napus as well as Picea orientalis plants that showed an improvement in yield and yield components as a result of zeolite addition to soil (Sing and Bhargava, 1994; Ayan et al., 2005). The improvement in yield and yield component may also be related to the increase in nitrogen availability and the prevention of nitrogen leaching. Zeolux presence had a higher effect on root dry weight than shoot dry weight, which resulted in a decrease in shoot to root ratio as zeolux percentage in soil increases.

\subsubsection{RO Reject as Irrigation Water}

Table 2 and Figures 1-6 show that the effects of zeolux mixing with clay soil on plant height, shoot fresh weight, shoot dry weight and root dry weight were absent for plants irrigated with RO reject water. Although the presence of zeolux has improved the value of SDW/RDW and the presence of $25 \%$ zeolux has increased the number of branches as compared to clay soil alone, the slight improvement does not justify the use of zeolux for these purposes.

\subsection{Effect of the Water Type}

Statistical analysis indicated that there is a significant effect of the water type on plant growth and production (Table 3). Irrigation of sage plants with RO reject water has been found to affect all yield components negatively. Plants irrigated with saline water exhibited $66 \%, 79 \%, 94 \%, 95 \%$ and $85 \%$ reduction over control in plant height, number of branches per plant, shoot fresh weight, shoot dry weight and root dry weight, respectively (Table 3 ). 
Table 3: Mean plant height (PH), number of branches per plant (NB), shoot fresh weight (SFW), shoot dry weight (SDW), root dry weight (RDW) and the ratio between shoot dry weight and root dry weight (SDW/RDW) of Sage plant (Salvia officinalis) under two types of water§.

\begin{tabular}{ccccccc}
\hline \multirow{2}{*}{ Type of water } & \multicolumn{7}{c}{ Mean square } \\
\cline { 2 - 7 } & PH & NB & SFW & SDW & RDW & SDW/RDW \\
\hline Fresh & $43.05 \mathrm{~A}$ & $19.2 \mathrm{~A}$ & $67.3 \mathrm{~A}$ & $20.36 \mathrm{~A}$ & $6.16 \mathrm{~A}$ & $3.40 \mathrm{~B}$ \\
\hline RO reject & $14.4 \mathrm{~B}$ & $4.05 \mathrm{~B}$ & $3.43 \mathrm{~B}$ & $0.98 \mathrm{~B}$ & $0.25 \mathrm{~B}$ & $4.03 \mathrm{~A}$ \\
\hline LSD (p $\leq \mathbf{0 . 0 5 )}$ & 2.08 & 1.22 & 2.59 & 0.76 & 0.24 & 0.39 \\
\hline
\end{tabular}

$\S$ Within columns, means followed by different letters suggest that the difference is significant at the 0.05 probability using LSD test.

The decrease of measured vegetative parameters can be explained by the fact that irrigation with saline water inhibits water uptake and crop nutritional elements from soil via roots. Salinity causes growth reduction due to the low osmotic potential of the medium and by specific ion effect as a secondary cause (Hendawy and Khalid, 2005). The response of plant growth to salinity follows two phases. The first is an exterior effect that decreases root zone osmotic potential (Munns et al., 1995). This leads to water stress in plants and growth is probably reduced by inhibitory signals from roots (Munns, 2002). The second phase of growth reduction is due to salts being concentrated within the plant (Munns et al., 1995).The decreased in the vegetative growth characters of Sage (Salvia Officinalis) as a result of soil salinity are in agreement with previous reports (Sari and Ceylan, 2002; Ozturk et al., 2004). The effect of salinity was higher on root more than shoot resulting in increased shoot /root ratio from 3.4 to 4.03 (Table 3). This observation was confirmed for Bell Pepper seedlings (Morales-Garcia et al., 2008) which could be a consequence of a higher accumulation of $\mathrm{Na}+$ in roots than in shoots (Blom-Zandstra et al., 1998). Decreasing in the root/shoot ratio have also been reported for other seedlings grown under saline conditions (Al-Harbi, 1995; Rodriguez et al., 1997; Yildirim and Guvenc, 2006). Salinity reduces root development, water uptake as well as transpiration and respiration which results in perished hormonal balance, altered photosynthesis rate, decreased nitrate uptake, and cell growth. Overall, plant response to the above mentioned reduced physiological conditions occurs in yield and its components (Sonneveld et al., 1999; Wahome et al., 2000; Shillo et al., 2002; Paradiso et al., 2003; De Lucia et al., 2003; Grieve et al., 2005). The presence of zeolux as soil amendment could not reduce any of these negative effects of salinity at this high value of TDS.

\section{Conclusions}

Zeolux mixing with clay has been found to improve the yield and agronomic traits of sage plant when irrigated with fresh water. At a mixture of $25 \%$ zeolux and $75 \%$ clay, which gave the best results, an increase of $29 \%$ in plant height, $76 \%$ in shoot fresh weight, $44.9 \%$ in shoot dry weight and $49 \%$ in root dry weight of sage plant were observed as compared with clay soil alone. When fresh water was used for irrigation, zeolux mixing with clay resulted in $48.8 \%, 58.8 \%, 59.5 \%$ and $66 \%$ increase in root dry weight of sage plant as compared to clay soil alone when zeolux percentage in soil the percentage were $25 \%, 50 \%$, $75 \%$ and $100 \%$ respectively. As zeolux percentage in soil increases, the shoot dry weight to root dry weight decreases indicating a higher drought resistance of sage plant. On the other hand mixing clay soil with zeolux did not reduce the harmful effect of $\mathrm{RO}$ reject brine water used for irrigation of the sage plant.

\section{Acknowledgement}

This research would not have been possible without the financial support from the Scientific Research Support Fund (SRF) under the project of utilization of Jordanian volcanic tuff in different engineering applications.

\section{References}

Al-Harbi A.R. (1995), Growth and nutrient composition of Tomato and Cucumber seedlings as affected by sodium chloride salinity and supplemental calcium, J. Plant Nutr., 18, 1403-1416. 
APHA, 1995. Standard methods for the examination of water and wastewater.

Ayan S., Yahyaoglu Z., Gercek V. and Şahin A. (2005), Utilization of zeolite as a substrate for containerised oriental spruce (Picea orientalis L.) seedlings propagation. International Symposium on Growing Media. INRA-INH University d' Angers, 4-10, Angers-France.

Baricevic D. and Bartol T. (2000), The biological/ pharmacological activity of the Salvia genus. In: Kintzios, S.E. (Ed.), SAGE. The Genus Salvia. Harwood Academic Publishers, Amsterdam, pp.143-184.

Bauder J.W. and Brock T.A. (2001), Irrigation and quality, soil amendment, and crop effects on sodium leaching, Arid Land Research and management, 15, 1101-1133.

Bernier P.Y., Lamhamedi M.S. and Simpson D.G. (1995), Shoot:Root ratio is of limited use in evaluating the quality of container conifer stock, Tree Planters' Notes, 46(3), 102-106.

Blom-Zandstra M., Vogelzang S.A. and Veen B.W. (1998), Sodium fluxes in sweet pepper exposed to varying sodium concentrations, J. Exp. Bot., 49, 1863-1868.

De Lucia B., Mancini L. and Ventrelli A. (2003), Effects of nutrient solution salinity ( $\mathrm{NaCl}$ ) on the yield level and quality characteristics in Lilium Soilless culture, Acta Horticulturae, 609, 401-406.

Dwyer J. and Dyer A. (1984), Zeolites-An Introduction, Chem. Ind., 2 Apr. 1984, 237-240.

Grieve C.M., Poss J.A., Grattan S.R., Shouse P.J., Lieth J.H. and Zeng L. (2005), Productivity and mineral nutrition of limonium species irrigated with saline wastewaters, Hort. Science, 40, 654-658.

Hasegawa P.M., Bressan R.A., Zhu J.K. and Bohnert H.J. (2000), Plant cellular and molecular responses to high salinity, Annu Rev Plant Physiol Plant Mol Biol., 51, 463-499.

Hendawy S.F. and Khalid K.A. (2005), Response of sage (Salvia Officinalis L.) plants to zinc application under different salinity levels, Journal of Applied Sciences Research, 1(2), 147-155.

Kaya M.D., Okcu G., Atak M., Cikili Y. and Kolsarici O. (2006), Seed treatments to overcome salt and drought stress during germination in sunflower (Helianthus annuus L.), European Journal of Agronomy, 24(4), 291-295.

Loreto F., Centritto M. and Chartzoulakis K. (2003), Photosynthetic limitations in olive cultivars with different sensitivity to salt stress, Plant, Cell and Environment, 26, 595-601.

Maas E.V. (1993), Salinity and citriculture, Tree Physiology, 12, 195-216.

Morales-Garcia D., Stewart K.A. and Seguin P. (2008), Effects of saline water on growth and physiology of Bell Pepper seedlings, International Journal of Vegetable Science, 14(2), 121-138.

Munns R. (2002), Comparative physiology of salt and water stress, Plant, Cell and Environment, 25, 239-250.

Munns R., Schachtman D.P. and Condon A.G. (1995), The significance of a 2-phase growth-response to salinity in wheat and barley, Aust. J. Plant Physiol., 22, 561-569.

Noori M., Zendehdel M. and Ahmadi A. (2006), Using natural zeolite for the improvement of soil salinity and crop yield, Toxicological \& Environmental Chemistry, 88(1), 77-84.

Ozturk A., Unlukara A., Ipek A. and Gurbuz B. (2004), Effects of salt stress and water deficit on plant growth and essential oil content of lemon balm (Melissa Officinalis L.)., Pak. J. Bot, 36(4), 787-792.

Paradiso R., De Pascale S., Aprea F. and Barbieri G. (2003), Effect of electrical conductivity levels of nutrient solution on growth, gas exchanges and yield of two gerbera cultivars in soilless system, Acta Horticulturae, 609, 165-171.

Rodriguez P., Dell'Amico J., Morales D., Sánchez Blanco M.J. and Alarcón J.J. (1997), Effects of salinity on growth, shoot water relations and root hydraulic conductivity in tomato plants, J. Agr. Sci., 128, 439-444.

Sánchez A.S., Nogueira I.B.R. and Kalid R.A. (2015), Uses of the reject brine from inland desalination for fish farming, Spirulina cultivation, and irrigation of forage shrub and crops, Desalination, 364, 96-107.

Sari A.O. and Ceylan A. (2002), Yield characteristics and essential oil composition of lemon balm (Melissa officinalis L.) Grown in the Aegean Region in Turkey, Tr. J. of Agric. and Forestry, 26(4), 217-224.

SAS. 2002. SAS user's guide: Statistics version 9 for windows.SAS Institute. Carry, NC.

Shillo R., Ding M., Pasternak D. and Zaccai M. (2002), Cultivation of cut flower and bulb species with saline water, Scientia Horticulturae, 92, 41-54.

Sing H.C. and Bhargava S.C. (1994), Changes in growth and yield components of brassica napus in response to azotobacter inoculation at different rates of nitrogen application, Journal of Agriculture Science, 122, 241-247. 
Sonneveld C., Baas R., Nijssen H.M.C. and De Hoog J. (1999), Salt tolerance of flower crops grown in soilless culture, Journal of Plant Nutrition, 22, 1033-1048.

Tadros M.J., Al-Mefleh N. and Mohawesh O. (2012), Effect of irrigation water qualities on Leucaena leucocephala germination and early growth stage, International Journal of Environmental Science and Technology, 9(2), 281-286.

Wahome P.K., Jesch H.H. and Grittner I. (2000), Effect of the $\mathrm{NaCl}$ on the vegetative growth and flower quality of roses, Journal of Applied Botany, 74, 38-41.

Wilson J.B. (1988), A review of evidence on the control of shoot : root ratio, in relation to models, Annals of Botany, 61(4), 433-449.

Yildirim E. and Guvenc I. (2006), Salt tolerance of pepper cultivars during germination and seedling growth, Turk. J. Agr. Forest., 30, 347-353. 